\title{
DETECÇÃO DE SALMONELLA SPP COM O MEIO SEMISSÓLIDO RAPAPPORT VASSILIADIS (MSRV) EM TUBOS
}

\author{
Degenhardt $\mathrm{R}^{*}$, Franchin $\mathrm{PR}^{* *}$
}

Resumo

As salmonelas não tifoides são ainda consideradas os principais micro-organismos causadores de doenças de origem alimentar em todo o mundo, sendo ovos e a carne de aves os principais alimentos envolvidos nos surtos. A detecção do patógeno em toda a cadeia de produção é uma importante atividade em vistas ao seu controle. Portanto, métodos seguros, rápidos e de baixo custo são se grande valia para os microbiologistas. Objetivou-se a validação de uma forma alternativa da utilização do Meio Semissólido Rappaport Vassiliadis, descrito na ISO 6579:2002/Amd. 1:2007-Anexo D. A proposta modificou o enriquecimento seletivo do meio MSRV em placas para a alternativa utilizando o meio de cultura em tubo de ensaio, no qual se introduziu um tubo de Craige para a distinção da motilidade. Foram analisadas 307 amostras simultaneamente pela metodologia original e pela alternativa proposta. As análises permitiram a detecção de Salmonella spp em 33, e a avaliação estatística não demonstrou diferença entre as duas formas de emprego do meio semissólido ( $\alpha=0,4795$ ), sendo determinada a acurácia relativa (AC) de 99,35\%, a sensibilidade relativa (SE) de 93,97\% e a especificidade relativa (SP) de 100\%. Portanto, o método alternativo proposto pode ser empregado pela sua equivalência e vantagens adicionais que a forma alternativa de emprego do MSRV confere à análise.

Palavras-chave: Microbiologia de alimentos. Métodos de análise. ISO 6579.

\footnotetext{
* Mestre em Ciência dos Alimentos pela Universidade Federal de Santa Catarina; Graduado em Ciências Biológicas pela Universidade Federal de Santa Catarina; Professor da Área das Ciências Biológicas da Universidade do Oeste de Santa Catarina; roberto.degenhardt@ unoesc.edu.br

** Doutor em Ciência dos Alimentos pela Universidade Federal de Santa Catarina; Mestre em Ciência dos Alimentos pela Universidade Federal de Santa Catarina; Professor colaborador pesquisador da Universidade do Oeste de Santa Catarina; Rua Getúlio Vargas, 2125, Flor da Serra, 89600-000, Joaçaba, Santa Catarina, Brasil; paulofranchin@yahoo.com.br
} 


\title{
Salmonella spp detection with Semisolid Rapapport - Vassiliadis Medium (MSRV) in tubes
}

\author{
Abstract
}

Non-typhoid Salmonella is still the main micro-organism responsible for food-borne diseases worldwide, with poultry meat and eggs as the main food sources involved in outbreaks. The detection of the pathogen in all of the production chain is an important activity for its control; therefore safe, fast, low cost methods are very valuable to microbiologists. The objective of this study was the validation of an alternative use of modified semisolid Rappaport Vassiliadis, described in ISO 6579:2002/Amd. 1:2007-Annex D. The proposal modified the selective enrichment of MSRV in plates to the alternative using culture means in test tubes, introducing a Craige tube for distinguishing motility. We analyzed 307 samples simultaneously using the original method and the alternative proposal. The analyses detected Salmonella spp in 33 samples, and statistical analysis did not present differences between the two uses of modified semisolid ( $\alpha=0.4795)$, with $99.35 \%$ relative accuracy $(R A), 93.97 \%$ relative sensibility $(R S)$ and $100 \%$ relative specificity (RSp). Therefore, the proposed alternative method may be applied given its equivalency and additional advantages that the alternative MSRV employment method confers to the analysis.

Keywords: Microbiology of foods. Methods of analysis. ISO 6579.

\section{INTRODUÇÃO}

Durante as últimas décadas, as salmonelas não tifoides têm sido implicadas como a principal causa de infecções gastrintestinais humanas associadas ao consumo de alimentos e água em todos os países. ${ }^{1}$ No Brasil, essa condição se reafirma e os dados do Ministério da Saúde estimam que esse micro-organismo foi responsável pela maioria dos casos de doenças de origem alimentar no período de 2000 a $2011 .^{2}$

A principal forma de transmissão ocorre pela rota fecal-oral, na qual os alimentos participam ativamente como o principal veículo para o micro-organismo. Entretanto, outras formas de transmissão, em que o alimento ou água não são os veículos, não devem ser descartadas, como o contato com animais ou humanos portadores, objetos contaminados ou atividades nas quais há a manipulação de material com alta carga bacteriana, sendo esses casos menos frequentes e, principalmente, relacionados a descuidos de higiene. ${ }^{3,4,5}$ A detecção e quantificação de um micro-organismo é uma das principais ações a serem desenvolvidas para seu controle na cadeia epidemiológica. ${ }^{6}$ Várias alternativas de metodologias estão disponíveis no mercado para a detecção de Salmonella spp. ${ }^{7,8,9}$

O Meio Semissólido Rapaport Vassiliadis constitui uma alternativa ao método tradicional descrito na ISO 6579:2002 para a detecção de Salmonella em diferentes matrizes. Os primeiros trabalhos citando esse meio de cultura descrevem sua utilização com um teste rápido e sensível para o isolamento de salmonelas móveis em alimentos após o pré-enriquecimento em meio não seletivo ou 
mesmo seletivo. ${ }^{10,11,12}$ A condição de meio semissólido permite que a motilidade da Salmonella seja detectada formando halos facilmente identificados em razão da sua multiplicação em torno do ponto original de inoculação.

Esse método de detecção é oficial para a detecção de Salmonella em amostras ambientais (água, esgotos, solos) pela Agência de Proteção Ambiental dos Estados Unidos. ${ }^{13,14}$ Também é indicado para o isolamento do patógeno em fezes e amostras da produção primária. ${ }^{15,16}$ A Associação Europeia de Fabricantes de Chocolate recomenda-o como meio seletivo para o isolamento de Salmonella em chocolate e produtos correlacionados, assim como o Instituto de Pesquisa Americano do Cacau e a Associação dos Fabricantes Canadenses de Chocolate, os quais, por meio de um estudo colaborativo da AOAC Internacional, resultou na adoção do método MSRV. ${ }^{12} \mathrm{Na}$ Europa, o meio MSRV vem sendo avaliado desde 2009 pelo Instituto Nacional para a Saúde Pública (RIVM - Holanda). Os trabalhos de validação estão sendo realizados em colaboração com diversos laboratórios europeus, a fim de verificar seu emprego como método oficial para análise de carne de gado e de frango, cujos resultados preliminares demonstram ser muito promissores. ${ }^{17}$

Desde seu desenvolvimento, esse meio de cultura vem sendo utilizado crescentemente em virtude dos bons resultados e da facilidade para utilização em alimentos, ${ }^{18,19}$ rações, ${ }^{20,21}$ sanidade animal, ${ }^{22,23,24,25,26,27,28}$ amostras clínicas, ${ }^{29,18}$ ambiente $^{30,31}$ ou água. ${ }^{32,33}$

O objetivo deste trabalho foi avaliar uma alternativa ao emprego do Meio Semissólido Rappaport Vassiliadis em placas, substituindo as placas de Petri por tubos de ensaio, adaptando a metodologia sugerida por Harvey e Price $^{34}$ (Figura 1).

Figura 1 - Apresentação da utilização original do tubo de Craigie

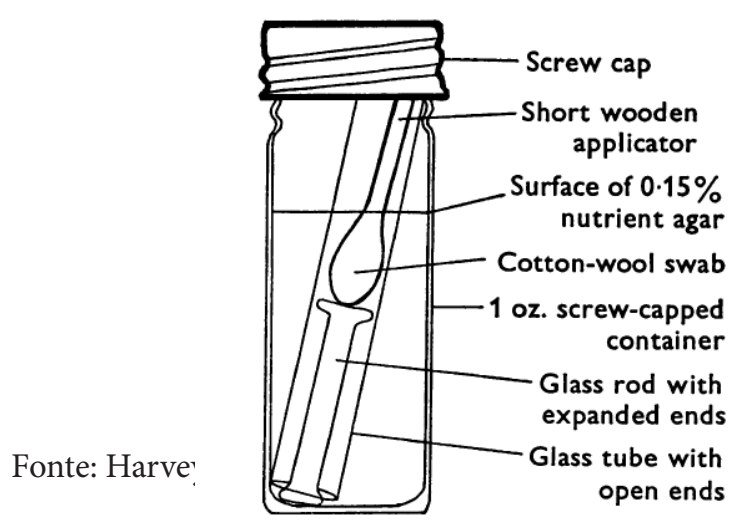

\section{MATERIAIS E MÉTODOS}


O protocolo de validação utilizado foi baseado na ISO 16140 (Protocol for the validation of alternative microbiological methods), conforme a Figura 2, e o método de referência para detecção de Salmonella foi o ISO 6579:2002/Amd 1:2007. Os ensaios foram realizados empregando-se como matrizes de análise carne e vísceras comestíveis de frango $(\mathrm{n}=158)$, farinha de vísceras de aves e suínos $(\mathrm{n}=52)$; amostras ambientais coletadas com esponjas $(\mathrm{n}=41)$; carne e vísceras de suínos $(\mathrm{n}=$ 38) e água do processo de resfriamento de carcaças de frango $(n=18)$, totalizando 307 amostras. As amostras foram obtidas em plantas de abate de aves e suínos localizadas no Estado de Santa Catarina.

Figura 2 - Protocolo do enriquecimento seletivo para validação da análise de Salmonella spp. conforme a ISO 16140

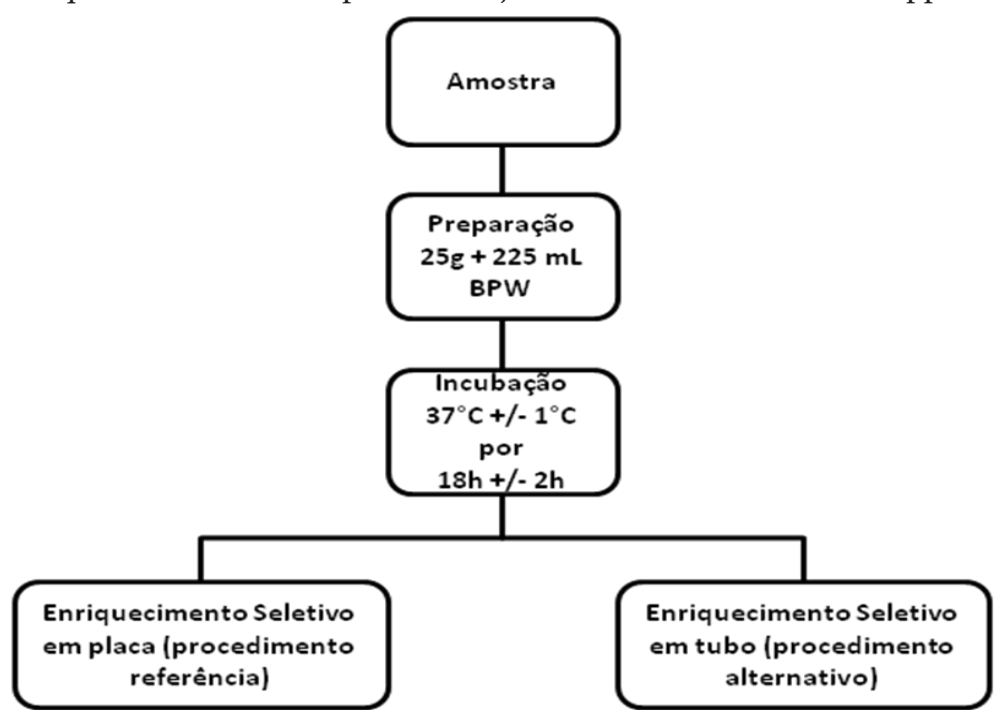

Fonte: adaptada de International Standard Organization. ${ }^{35}$

\subsection{PREPARAÇÃODAS AMOSTRASEENRIQUECIMENTOPRIMÁRIO NÃOSELETIVO}

As amostras foram recebidas no laboratório, resfriadas e analisadas em um prazo inferior a 24 horas após a coleta. Das amostras de carne foi retirada uma porção teste representativa de 25 gramas e homogeneizada com $225 \mathrm{~mL}$ de Água Peptonada Tamponada (APT - MERCK cód. 1.07228). A preparação das amostras de água constitui-se da tomada de uma porção teste de $100 \mathrm{~mL}$ de amostra, à qual foi adicionada $50 \mathrm{~mL}$ de APT em concentração tripla, e às amostras ambientais foi adicionado 100 $\mathrm{mL}$ de APT. Todas as amostras foram homogeneizadas em homogeneizador peristáltico por 1 minuto. Após a homogeneização, as amostras foram incubadas a $37^{\circ} \mathrm{C}\left(+/-1^{\circ} \mathrm{C}\right)$ por 18 horas $(+/$ - 2 horas).

\subsection{ENRIQUECIMENTO SELETIVO (MÉTODO DE REFERÊNCIA)}

Após o período de pré-enriquecimento, as culturas em APT foram inoculadas em Meio Semissólido Rappaport Vassiliadis (Acumedia cód. 7511). Conforme o método de referência, transferiu-se uma alíquota de $100 \mu \mathrm{L}$ da cultura em APT, tomando-se o cuidado para não provocar movimentação excessiva das partículas suspensas, e distribuiu-se em três pontos equidistantes na 
superfície no meio MSRV. As placas foram, então, incubadas em estufa com circulação de ar ajustada a $41,5^{\circ} \mathrm{C}\left(+/-1^{\circ} \mathrm{C}\right)$ por 24 horas (+/- 3 horas). Quando não eram observados resultados positivos após as primeiras 24 horas de incubação as placas eram incubadas por um período adicional de 24 horas.

\subsection{ENRIQUECIMENTO SELETIVO (MÉTODO ALTERNATIVO)}

O método alternativo consistiu na substituição das placas de Petri contendo aproximadamente $20 \mathrm{~mL}$ de meio MSRV por tubos de ensaio $(20 \times 150 \mathrm{~mm}$ ) contendo $8 \mathrm{~mL}$ de MSRV, formando uma coluna de aproximadamente $3 \mathrm{~cm}$ de altura. Após a transferência do meio de cultura para os tubos estéreis, foi colocada uma ponteira estéril de plástico (BRAND cód. 7025) com a ponta cortada em bisel, semelhante a um Tubo de Craige, conforme a Figura 3.

Figura 3 - Proposta de adaptação do Tubo de Craigie

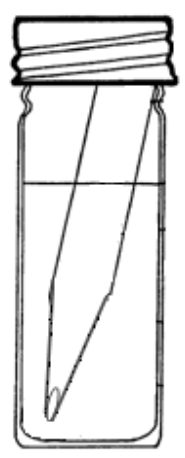

Fonte: adaptada de Harvey e Price..$^{34}$

A alíquota de $100 \mu \mathrm{L}$ da cultura de pré-enriquecimento foi transferida para o interior da ponteira inserida no meio MSRV de forma que o líquido entrasse em contato com o meio de cultura. Os tubos foram incubados em banho-maria ajustado a $41,5^{\circ} \mathrm{C}\left(+/-1{ }^{\circ} \mathrm{C}\right)$ por 24 horas (+/- 3 horas). Quando não eram observados resultados positivos, observados pela formação de uma zona branca acinzentada na superfície do meio de cultura, após as primeiras 24 horas de incubação, os tubos eram incubados por um período adicional de 24 horas.

\subsection{CONFIRMAÇÃO DAS CULTURAS POSITIVAS}

As culturas positivas no MSRV foram confirmadas por meio do isolamento em Ágar Xilose Lisina Desoxicolato (XLD - Merck cód. 1.05287) e Ágar Verde Brilhante (BPLS - Merck cód. 1.07232). As colônias características foram confirmadas por intermédio de provas bioquímicas (kit para identificação de enterobactérias - BACTRAY Laborclin ${ }^{\circledast}$ ) e sorológicas (Soro Polivalente Somático Probac), conforme a ISO 6579:2002. 


\subsection{ANÁLISE DOS DADOS}

Os resultados dos ensaios foram analisados por meio da estatística de McNemmar para dados não paramétricos, no programa Statística 7.0, admitindo-se um erro padrão de $5 \%(\alpha=0,05)$. A acurácia relativa (correspondência entre a resposta obtida pelo método de referência e a resposta do método alternativo) foi calculada empregando-se a Equação 1, enquanto a sensibilidade relativa (fração do total de resultados corretamente identificados pelo método alternativo) foi obtida empregando-se a Equação 2 e a especificidade relativa (fração do total de negativos corretamente identificados) foi determinada pela Equação 3 (ISO, 2000; ISO, 2003) 36,35.

Equação 1: Acurácia Relativa $(\mathrm{AC})=(\mathrm{PA}+\mathrm{NA}) / \mathrm{N}$ x 100

Equação 2: Especificidade relativa (SP) $=\mathrm{NA} / \mathrm{N}-\mathrm{x} 100$

Equação 3: Sensibilidade relativa $(S E)=\mathrm{PA} / \mathrm{N}+\mathrm{X} 100$

Em que:

$\mathrm{PA}=$ Número de resultados positivos nos dois métodos utilizados;

$\mathrm{NA}=$ Número de resultados negativos nos dois métodos utilizados;

$\mathrm{N}$ - = Total de resultados negativos obtidos pelo método de referência;

$\mathrm{N}+=$ Total de resultados positivos obtidos pelo método de referência;

$\mathrm{N}=$ Número de amostras analisadas.

\section{RESULTADOS E DISCUSSÃO}

Segundo a literatura, o enriquecimento seletivo com o meio MSRV é considerado há mais de uma década uma das melhores alternativas para o isolamento de salmonelas de amostras da produção primária, ${ }^{37}$ alimentos, ${ }^{38,39}$ água ${ }^{40}$ ou amostras clínicas. ${ }^{29}$

Os resultados dos ensaios realizados neste trabalho com matrizes de carne suína e de frango demonstraram um total de 33 amostras positivas para Salmonella spp e 274 amostras negativas, independentemente da forma de utilização do meio MSRV (em placa ou tubo). O método de referência (MSRV em placas) indicou as 33 amostras positivas, enquanto o método alternativo (MSRV em tubos) demonstrou 31 amostras positivas, assim, a Acurácia Relativa observada foi de 99,35\%, a Sensibilidade Relativa (SE) foi de 93,97\% e a Especificidade Relativa (SP) foi de 100\%. Não foi observada diferença estatística entre os dois métodos de enriquecimento seletivo estudados $(\alpha=0,4795)$.

Os parâmetros acurácia, sensibilidade e especificidade podem ser considerados adequados quando comparados com outros estudos que compararam o meio MSRV com outras metodologias, conforme Franchin et al. ${ }^{39}$ e Coelho. ${ }^{8}$ 
Em relação ao tempo de incubação do meio MSRV, pelo método de referência, obtiveram-se os 33 resultados positivos com 24 horas de incubação, e, considerando as 31 amostras que tiveram resultado positivo correspondente entre os dois métodos, pelo método alternativo, 23 apresentaram resultado positivo nas primeiras 24 horas de incubação e as outras 8 amostras necessitaram 24 horas adicionais de incubação.

Como vantagens ao método de enriquecimento seletivo proposto, destacam-se:

a) menor espaço em estufas para incubação: quando o meio semissólido é utilizado em placas, existe a limitação de empilhamento e distribuição delas no interior da estufa incubadora, conforme determina a ISO 7218, ${ }^{16}$ ao contrário da utilização em tubos de ensaio, que ocupam um espaço menor e quando alocados em estantes apropriadas permitem a melhor circulação do ar e manutenção da temperatura.

b) possibilidade de incubação em banho-maria: permite melhor homogeneidade da temperatura de incubação. Destaca-se que a homogeneidade de temperatura e controle nas oscilações de temperatura ocasionadas por abertura de estufas são pontos críticos desse método de detecção de Salmonella;

c) facilidade na observação dos tubos presuntivamente positivos: as alterações no meio de cultura ocasionada pela migração decorrente da multiplicação de Salmonella são mais bem distinguidas, pois a área da inoculação da alíquota de cultura pré-enriquecida é independente da região na qual é observada a migração (Figura 4);

Figura 4 - Representação da migração das células de Salmonella móveis no procedimento proposto para enriquecimento em meio MSRV em tubos

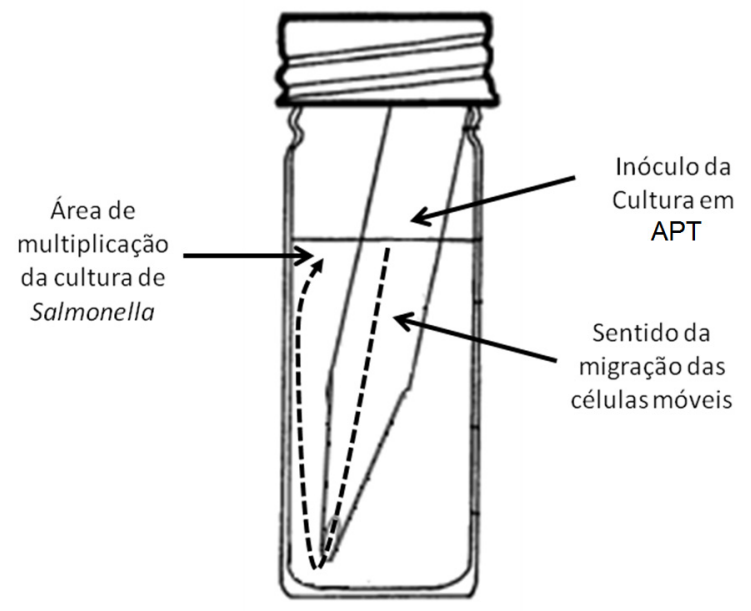

Fonte: os autores.

d) integridade da estrutura do meio de cultura: quando o meio semissólido é empregado em placas de Petri, a movimentação decorrente de sua manipulação pode provocar microfissuras no gel que acarreta crescimentos irregulares de outras entrebaterias, induzindo a resultados 
falso-positivos. Quando o meio semissólido é empregado em tubos, o gel não sofre com choques mecânicos leves da mesma forma que em placas de Petri;

e) estabilidade osmótica por menor perda de água: a menor superfície de contato do meio de cultura em tubos de ensaio com o ar diminui a perda de água e, portanto, a manutenção das concentrações adequadas de sais e nutrientes, além da diminuição de oxidação.

As desvantagens observadas do método proposto são a preparação mais demorada do meio de cultura, exigindo maior manipulação na transferência do meio fluido para os tubos de ensaio e introdução da ponteira e maior manipulação na inoculação da alíquota de cultura em APT, pois exige o desrosqueamento da tampa e rosqueamento posterior para fechá-lo, e, ainda, a possibilidade de menor detecção de amostras positivas em 24 horas de incubação.

\section{CONCLUSÃO}

Os resultados obtidos neste trabalho demonstram que o método alternativo de enriquecimento seletivo com o Meio Semissólido Rapapport Vassiliadis em tubos de ensaio, associados a tubos de Craige, em substituição ao método original, não apresenta diferença estatística significativa. Essa proposta apresenta, ainda, vantagens adicionais relacionadas à execução dos ensaios, e, embora a preparação do meio de cultura em tubos e a inoculação da cultura pré-enriquecida sejam mais trabalhosas, os benefícios são superiores aos obtidos pelo método original. Essa adaptação do método original pode ser utilizada em diversos segmentos de diagnóstico de Salmonella, entretanto, a aplicação em matrizes diferentes necessita da sua validação.

\section{REFERÊNCIAS}

1. Puig, PY, Espino HM, Leyva CV, Aportela LN, Machín DM, Soto RP. Serovariedades y patrones de susceptibilidad a los antimicrobianos de cepas de Salmonella aisladas de alimentos en Cuba. Rev Panam Salud Publica. 2011; 30(6):561-565.

2. Secretaria de Vigilância em Saúde. Ministério da Saúde. Vigilância Epidemiológica das Doenças de Transmissão Hídrica e Alimentar - VEDTHA [Internet]. 2011 [acesso em 2013 maio 14]. Disponível em: http://portal.saude.gov.br/portal/arquivos/pdf/10_passos_para_investigacao_surtos.pdf

3. Megid J, Assis MZ de, Brito CJ, Lara VM. Salmonelose em cães de experimentação. Braz J Vet Res Anim Sci. 2001; 38(1).

4. Doughari JH, Okafor NB. Antibacterial activity of Senna siamae leaf extracts on Salmonella typhi. Afr J Microbiol Res. 2008 Feb; 2:42-46.

5. Pereira JAP, Lima TBN, Siqueira LP, Shinohara KS, Paiva JE. Avaliação bacteriológica da água de consumo em unidades de alimentação do Recife, PE. Higiene Alimentar. 2010 nov-dez; 24(190/191):105-108. 
6. Cardoso ALSP, Tessari ENC. Salmonella na Segurança dos Alimentos. Biológico. 2008 jan-jun; $70(1): 11-13$.

7. Andreatti Filho RL, Gonçalves GAM, Okamoto AS, Lima ET. Comparação de Métodos para Extração de DNA na Reação em Cadeia da Polimerase pra Detecção de Salmonella enterica sorovar Enteritidis em produtos avícolas. Ciênc Anim Bras. 2011 jan-mar; 12(1):115-119.

8. Coelho LR. Equivalência de Métodos Alternativos ao Oficial para Determinação de Salmonella Enteretidis e Typhimurium em Amostras Ambientais Avícolas [dissertação]. Minas Gerais: Universidade Federal de Uberlândia; 2012.

9. Odumeru JA, León-Velarde CG. Salmonella Detection Methods for Food and Food Ingredients. In: Mahmoud BSM (Org.). Salmonella - A Dangerous Foodborne Pathogen. [Internet]. Rijeka, Croatia: InTec; 2012. [acesso em 2015 ago 01]. Disponível em: http://www.intechopen.com/books/ salmonella-a-dangerous-foodborne-pathogen

10. De Smedt JM, Bolderdijk RF, Rappold H, Lautenschlaeger D. Rapid Salmonella detection in food by motility enrichment on a modified semi-solid Rappaport-Vassiliadis Medium. J. Food Prot. 1986; 49:510-514.

11. Smedt JM, Bolderdijk R. Dynamics of Salmonella isolation with modified semi-solid RappaportVassiliadis Medium. J. Food Prot. 1987; 50:658-661.

12. Smedt JM, Bolderdijk R, Milas J. Salmonella detection in cocoa and chocolate by motility enrichment on modified semi-solid Rappaport-Vassiliadis Medium: a collaborative study. J. AOAC Int. 1994; 77:365-373.

13. United States Environmental Protection Agency. Method 1682. Salmonella in Sewage Sludge (Biosolids) by Modified Semisolid Rappaport-Vassiliadis (MSRV) Medium. [Internet]. 2006 Jul. 48 p. [acesso em 2013 maio15]. Disponível em: http://water.epa.gov/scitech/methods/cwa/bioindicators/ upload/2008_11_25_methods_method_biological_1682.pdf

14. United States Environmental Protection Agency. Method 1200. Analytical Protocol for NonTyphoidal Salmonella in Drinking Water and Surface Water. [Internet]. 2012 May. 46 p. [acesso em 2013 maio 15]. Disponível em: http://water.epa.gov/infrastructure/watersecurity/wla/upload/ epa817r12004.pdf

15. Dusch H, Altwegg M. Evaluation of five new plating media for isolation of Salmonella species. J. Clin. Microbiol. 1995 abr; 33(4):802-804.

16. International Standart Organization. ISO 7218:2007. Microbiology of food and animal feeding stuffs - General requirements and guidance for microbiological examinations. Genève; 2007. 66 p.

17. National Institut Forpublic Health. The $19^{\text {th }}$ EURL - Salmonella Workshop. Bilthoven (NL): RIVM; 2014. 64 p. 
18. Bangtrakulnonth A, et al. Salmonella serovars from humans and other sources in Thailand, 19932002. Emerg Infect Dis. 2004 jan; 10(1):131-136.

19. Dutil L, Irwin R, Finley R, Ng LK, Avery B, Boerlin P, et al. Ceftiofur resistance in Salmonella enterica serovar Heidelberg in chicken meat and humans, Canada. Emerg Infect Dis. 2010 jan; $16(1): 48-54$.

20. Soria MC, Soria MA, Bueno DJ, Colazo JL. A comparative study of culture methods and polymerase chain reaction assay for Salmonella detection in poultry feed. Poult Sci. 2011 nov; 90(11):2606-2618.

21. Kuijpers AFA, Mooijman KA. Detection of Salmonella in food, feed and veterinary samples by EU laboratories. Food Res Int. 2012 mar; 45(2):885-890.

22. Carrique-Mas JJ, Barnes S, McLaren I, Davies R. Comparison of three plating media for the isolation of Salmonella from poultry environmental samples in Great Britain using ISO 6579:2002 (Annex D). J Appl Microbiol. 2009 dez; 107(6):1976-1983.

23. Wilkins W, Waldner C, Rajić A, McFall M, Chow E, Muckle A. Comparison of bacterial culture and real-time PCR for the detection of Salmonella in grow-finish pigs in Western Canada using a Bayesian approach. Zoonoses Public Health. 2010 nov; (57)(Suppl 1):115-20.

24. García C, Soriano JM, Benítez V, Catalá-Gregori P. Assessment of Salmonella spp. in feces, cloacal swabs, and eggs (eggshell and content separately) from a laying hen farm. Poult. Sci. 2011 jul; 90(7):1581-1585.

25. Vico JP, Rol I, Garrido V, San Román B, Grilló MJ, Mainar-Jaime RC. Salmonellosis in Finishing Pigs in Spain: Prevalence, Antimicrobial Agent Susceptibilities, and Risk Factor Analysis. J. Food Prot. 2011 jul; 74(7):1070-1078.

26. Nuvee Prapasarakul N, Pulsrikarn C, Vasaruchapong T, Lekcharoen P, Chanchaithong P, Lugsomya $\mathrm{K}$, et al. Salmonella serovar distribution in cobras (Naja kaouthia), snake-food species, and farm workers at Queen Saovabha Snake Park, Thailand. J Vet Diagn Invest. 2012 mar; 24(2):288-294.

27. Schultz J, Jarquin R, Ricke SC, Hanning I. Optimized culturing and nucleic acid-based methods for the detection of Salmonella enterica in poultry environments. Poult Sci. 2012 nov; 91(11):2761-2766.

28. De Busser EV, Maes D, Houf K, Dewulf J, De Zutter L. Effect of the enrichment medium on the detection and diversity of Salmonella from porcine duodenal content. Foodborne Pathogens and Disease. 2013; 2(10):182-188.

29. Arnnajsirisuk S. Comparative study between the standard media and Modified Semi-solid Rapaport Vassiliadis (MSRV) media on Salmonella isolation rater in Lampang Hospital. Lampang Med J. Tailand. 1998 Jan-Apr; 19(1):53-58.

30. Wan Wang YC, Chang YC, Chuang HL, Chiu CC, Yeh KS, Chang CC, et al. Transmission of Salmonella between Swine Farms by the Housefly (Musca domestica). J. Food Prot. 2011 Jun; 74(6): 
1012-1016.

31. Lungu B, Waltman WD, Berghaus RD, Hofacre CL. Comparison of a Real-Time PCR Method with a Culture Method for the Detection of Salmonella enterica Serotype Enteritidis in Naturally Contaminated Environmental Samples from Integrated Poultry Houses. J. Food Prot. 2012 Apr; 5(4):743-747.

32. Edge TA, El-Shaarawi A, Gannon V, Jokinen CC, Kent R, Khan IUH. Investigation of an Escherichia coli Environmental Benchmark for Waterborne Pathogens in Agricultural Watersheds in Canada. J. Environ. Qual. 2012 Jan; 41(1):21-30.

33. Soria MC, Soria MA, Bueno DJ. A comparative study of culture methods and PCR assay for Salmonella detection in poultry drinking water. Poult Sci. 2013 Jan; 92(1):225-232.

34. Harvey RWS, Price TH. The isolation of salmonelas from animal feedingstuffs. J Hyg Camb. 1967; (65):237-244.

35. International Standart Organization. ISO 16.140 - Microbiology of food and animal feeding stuffs - Protocol for the validation of alternative methods. Genève; 2003. 74 p.

36. International Standard Organization. ISO/TR 13843 - Water quality - Requirements for establishing performance characteristics of quantitative microbiological methods. Genève; 2000. 47 p.

37. Baggesen DL, Nielsen LR, Sørensen G, Bødker R, Ersbøll AK. Growth inhibitory factors in bovine faeces impairs detection of Salmonella Dublin by conventional culture procedure. J Appl Microbiol. 2007 Sep; 103(3):650-656.

38. Worcman-Barninka D, Destro MT, Fernandes SA, Landgraf M. Evaluation of motility enrichment on modified semi-solid Rappaport-Vassiladis medium (MSRV) for the detection of Salmonella in foods. Int J Food Microbiol. 2001 Mar; 64(3):387-393.

39. Franchin PR, Ogliari PJ, Andrade DF, Chiapinoto M, Lemos G, Rebelatto M, et al. Compariosion of the BAX ${ }^{\oplus}$ SYSTEM with an in-house MSRV method for detection of Salmonella in chicken carcasses and pork meat. Braz J Microbiol. 2006; 37(4):521-526.

40. Zdragas A, Tsakos P, Mavrogen IP. Evaluation of two assays, MSRV and RV, for the isolation of Salmonella spp. from wastewater samples and broiler chickens. Lett Appl Microbiol. 2000 Oct; 31(4):328-31. 
